\title{
Effect of Reduced Graphene Oxide Reinforcement on Creep Behavior of Adhesively Bonded Joints
}

\author{
Gholamreza MARAMI*, S. Adib NAZARI**, S. Ali FAGHIDIAN*, \\ Farid VAKILI-TAHAMI**** \\ *Department of Mechanical and Aerospace Engineering, Science and Research branch, Islamic Azad University, Tehran, Iran, \\ E-mail: gh.marami@srbiau.ac.ir \\ **Department of Aerospace Engineering, Sharif University of Technology, Tehran, Iran \\ ***Department of Mechanical Engineering, University of Tabriz, Tabriz, Iran \\ cross ref http://dx.doi.org/10.5755/j01.mech.23.5.19360
}

\section{Introduction}

Adhesively bonded joints are frequently used in design of light weight components such as vehicles and aircraft frames. Most of adhesives show viscoelastic behavior even at low temperature and low stress levels. Therefore studying the viscoelastic and creep behavior of the adhesively bonded connections is an important issue to increase durability of these joints [1].

Experimental studies reveal that epoxies show linear deformation below moderate stresses and with increasing loads, nonlinear deformation is observed [2]. Nonlinear behavior of the adhesives can be simulated using several viscoelastic models. The classical models of Voigt and Maxwell are known as the simplest viscoelastic models [3]. Improved Voigt and Maxwell models have also been introduced and commonly are used in the literature [4-7]. Majda and Skrodzewicz [8] have simulated nonlinear behavior of an epoxy adhesive using modified burger's model. Furthermore, some of researchers developed empirical models to simulate creep behavior of the adhesives for example Burger's model is composed of Maxwell and Kelvin-Voight models. Yu et al [9] developed an empirical approach to determine time dependent creep function of adhesives with viscoelastic behavior. Roseley et al [10] have simulated creep behavior of three types of adhesives using Kelvin-Voight equations. However, they have reported that this model cannot simulate the adhesive behavior above the adhesive's glass transition temperature.

Since experimental investigation of the creep behavior of the adhesively bonded joints are time consuming and expensive; hence, creep behavior of single lap bonded joints has been investigated using different analytical and finite element approaches [2, 11-14]. Pandey et al [15] analyzed the adhesive joints considering elasto-viscoplastic behavior of the adhesive. Ferrier et al [16] investigated the epoxy adhesives creep durability and performance which are applied to strengthen steel-reinforced concrete structures. Choi [17] presented a rheological model for a typical adhesive which is used to reinforce concrete beams. They experimentally showed that creep is the most significant failure reason of the concrete fiber reinforced polymers.

Due to the increasing application of adhesively bonded joints, numbers of studies are carried out to improve mechanical and thermal characteristics of the bonded joints. For instance, several studies show that introduction of small fraction of carbon nano tubes (CNTs) enhance mechanical properties of epoxies such as fracture tough- ness, ultimate strength, thermal and environmental durability [18-21]. Also recent studies show that polymers reinforced with CNT particles demonstrate enhanced creep resistance characteristics [22-25]. Although CNTs are known as excellent fillers due to their spectacular high strength and stiffness but they are very expensive to use. Recently, graphene has been introduced as a new nanomaterial which has high strength as nano-tubes and low cost as nano-clays [26]. Graphene, as a mono-ply of sp2 bonded carbon atoms has unique properties for example, it has enormous specific surface area $\left(2620 \mathrm{~m}^{2} \mathrm{~g}\right)$, high mechanical properties (Young's modulus of $1 \mathrm{TPa}$ and ultimate strength of $130 \mathrm{GPa}$ ), high thermal conductivity (above $300 \mathrm{~W} /(\mathrm{mK})$ ) and other properties which have been reported in the literature [27]. Therefore, adding graphene has recently attracted researchers' interest as one of the potential methods to improve creep resistance of the polymers. Zandiatashbar et al, [28] reported that graphene significantly increases the creep resistance of the epoxies comparing to the CNTs. Tang et al. [29] investigated the effects of chemically Reduced Graphene Oxide (RGO) sheets on the creep and recovery characteristics of the polystyrene composites. They compared the results with corresponding composites with CNTs and observed that RGO efficiently decrease the creep deformation comparing to the worse efficiency of the CNTs. Wang et al. [30] investigated the effect of added different weight fractions of RGO on the creep and recovery behavior of the polystyrene composites at different environmental temperatures. They have found that creep response and recovery drop with decreasing environmental temperature.

According to the author's literature research, so far, the effect of the added RGO on the creep behavior of the bonded joints have not been investigated yet. For example, Zehsaz et al [32] have investigated the creep behavior of adhesive bonded joints without adding any reinforcing elements. Hence, in this article the effect added reinforcing element: $0.5 \mathrm{wt} \% \mathrm{RGO}$ on the creep behavior of single lap adhesively bonded joints has been investigated. To this aim, bulk specimens of the neat adhesive and adhesive-RGO composite were manufactured to observe the influence of the added RGO on the creep characteristics of the adhesive. Then single lap joints with neat adhesive and adhesive-RGO mixture were produced. Using these specimens uni-axial creep tests are carried out and the creep deformations of the joints are recorded. Also, finite element based numerical models were developed to simulate the creep deformations of the lap joints. 


\section{Testing procedures}

Uniaxial creep tests were conducted on Araldite 2011 epoxy based adhesive. To investigate the effect of adding RGO, two sets of bulk specimens are produced: neat adhesive and adhesive-RGO composite. The procedure of mixing RGO additive has been fully described in our previous paper [31]. The required ratio of the RGO has been blended with epoxy resin for 3 hours in a Ball-Mill machine. Then epoxy hardener has been added to the mixture and bath-sonicated at $480 \mathrm{~Hz}$ for 10 minutes. Then the mixture was stored in a vacuum machine to remove the entrapped air during the mixing process. Bulk specimens were produced according to ASTM D638 recommendation and the method which has been described by Zehsaz et al [33]. In this method, the prepared adhesive and adhesiveRGO are casted in the molds of silicone sheet. Afterwards, samples were cured in a furnace at $67^{\circ} \mathrm{C}$ for 30 minutes and then kept for seven days at room temperature before creep testing.

Uniaxial tensile creep tests were conducted in Amsler creep testing machine and creep elongation of the specimens was measured using contact extensometers with the accuracy of $\pm 0.001 \mathrm{in}$. Fig. 1 presents the test configuration for a bulk specimen and a typical sample with its dimensions. It should be highlighted that the displacement and strain of the samples are measured between points " $A$ " and "B" (presented in Fig 1, c) using extensometers which operate during the test. In this part the cross section of the sample is constant; and hence, the deformation of the "pin holes" and the "end parts" of the sample are excluded in the calculating of the displacement and strain. Tests were conducted at $25^{\circ} \mathrm{C}$ and $55^{\circ} \mathrm{C}$ to obtain the response of the added RGO on the creep deformation in the room and high temperatures. It is worth noting that the glass transition temperature of the adhesive and adhesive-RGO is $67^{\circ} \mathrm{C}$ and $78^{\circ} \mathrm{C}[31]$, respectively.

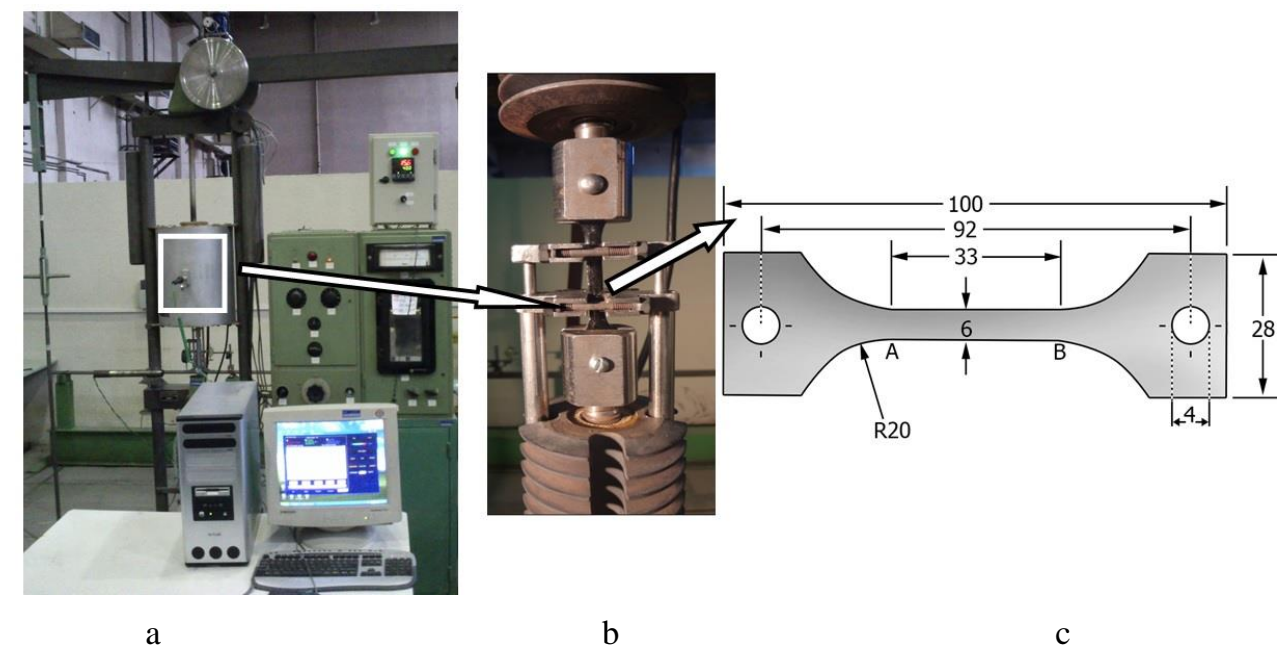

Fig. 1 Amsler creep testing machine (a), adhesive-RGO bulk specimen sample (b) and its dimensions (c)

To study the effect of RGO additive on the creep deformation of the bonded joints, single lap joints were manufactured according to ASTM D1002 using neat and modified adhesive. Lap joints were produced with $2 \mathrm{~mm}$ thickness aluminium alloy 7075-T6 plates.

Prior to the bonding, mating surfaces were treaded based on ASTM D1780 recommendations. Acetone is used to remove any contamination on the plat surfaces. Then the surfaces are treated with $\mathrm{SiC}$ abrasive paper and washed with water. Finally, adherends are etched with optimized FPL etch (Forest Products Laboratories SulfoChrome etch) [31]. Then, the adhesive was applied on the mating surfaces and the assembly is placed in a fixture to adjust the adhesive thickness and ensure the joint alignment. Finally, samples were stored in a furnace at $67^{\circ} \mathrm{C}$ for 35 minutes. To obtain identical samples, excess adhesive is removed and samples were kept for seven days before testing.

\section{Experimental data and numerical simulation}

\subsection{Bulk specimens and test results}

Uniaxial creep tests were conducted to evaluate the creep response of the modified adhesive with $0.5 \mathrm{wt} \%$
RGO additive. During the creep tests, elongation of the bulk specimens has been recorded and creep strain $\left(\varepsilon_{t o t}\right)$ is calculated using Eq. 1:

$$
\varepsilon_{c}(t)=\varepsilon_{\text {total }}(t)-\varepsilon_{e},
$$

where $\varepsilon_{e}$ is initial elastic strain and $\varepsilon_{c}$ is creep strain. Fig. 2 presents the creep curves for the neat adhesive and adhesive-RGO samples at $25^{\circ} \mathrm{C}$ and $55^{\circ} \mathrm{C}$ and at different stress levels. It is noted that tests at $25^{\circ} \mathrm{C}$ were stopped after 12 days. As it can be seen in these figures, incorporation of RGO particles remarkably improves the creep resistance of the adhesive by decreasing the creep strain at the same temperature and stress levels. Also, this figure shows that application of RGO increases creep failure time of the modified adhesive comparing to the neat adhesive. To highlight this effect, in Fig. 2 e, creep strain curves for the neat adhesive and adhesive- $\mathrm{RGO}$ at $25^{\circ} \mathrm{C}$ and $8 \mathrm{MPa}$ are compared to show the effect of adding RGO. It can be seen that adhesive-RGO strained to 0.062 after 45 hours whereas neat adhesive is strained up to 0.13 after 41 hours. 


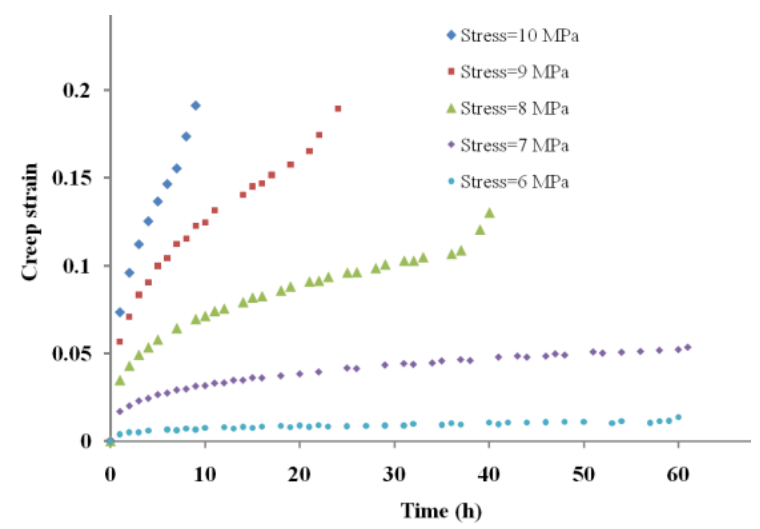

a

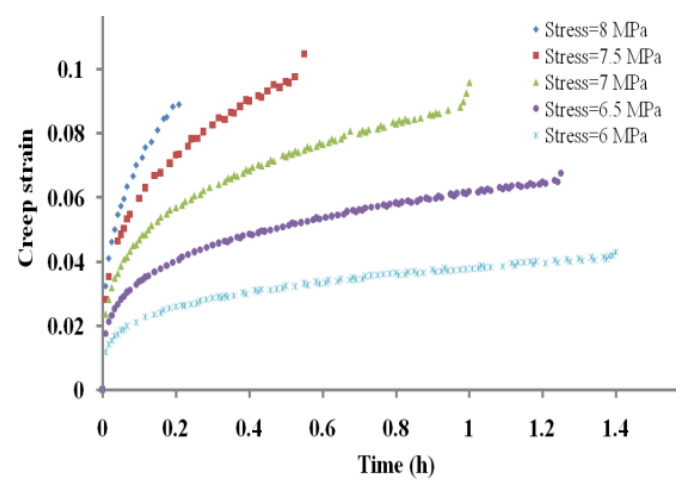

$\mathrm{c}$

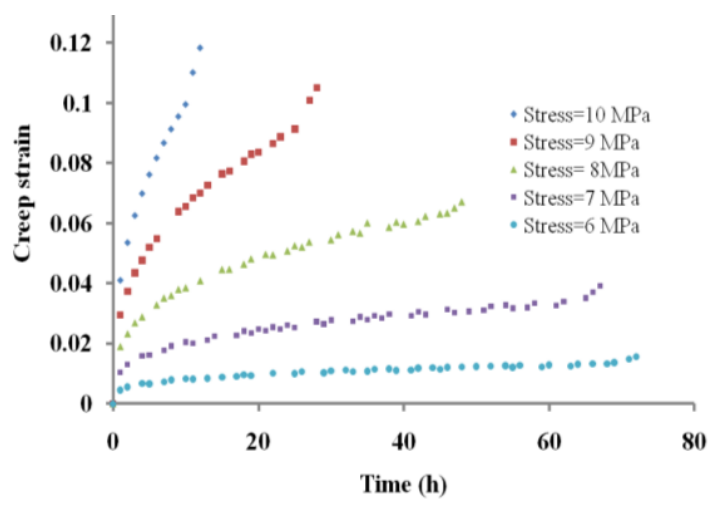

$\mathrm{b}$

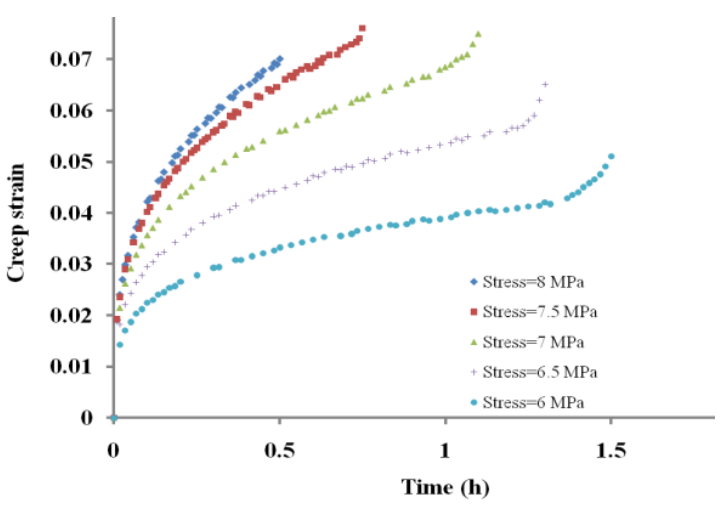

$\mathrm{d}$

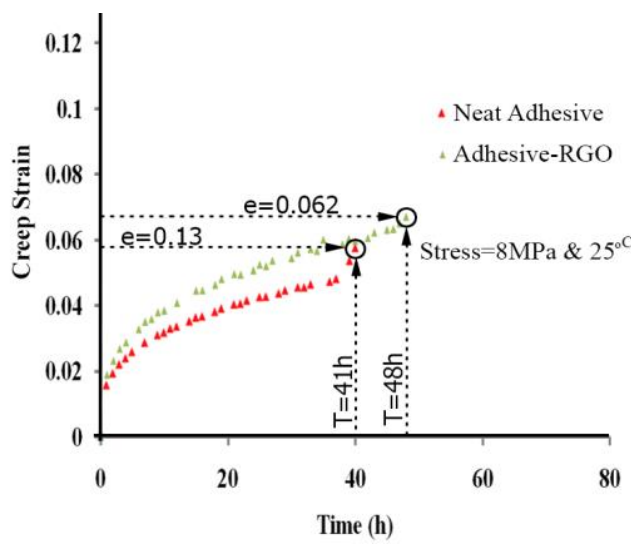

e

Fig. 2 Creep strain curves (a): neat adhesive at $25^{\circ} \mathrm{C}$; (b): adhesive-RGO at $25^{\circ} \mathrm{C}$; (c): neat adhesive at $55^{\circ} \mathrm{C}$; (d): adhesiveRGO at $55^{\circ} \mathrm{C}$; (e): comparison of the creep strain curves for neat adhesive and adhesive-RGO at $25^{\circ} \mathrm{C}$ and $8 \mathrm{MPa}$ showing the effect of adding RGO

To perform stress analysis in the bonded joint, generalized time hardening model:

$$
\varepsilon_{c r}=\left(D_{1} \sigma+D_{2} \sigma^{2}+D_{3} \sigma^{3}\right) t^{\left(D_{4}+D_{5} \sigma\right)}
$$

is used to simulate the creep behavior of the bulk specimens. Zehsaz et al. [32] demonstrated that generalized time hardening model can accurately simulate the creep behavior of the epoxy based adhesive in room and high temperature. This model is capable of simulating the creep behavior of variety of materials in wide range of stress and temperature levels. In this model $\sigma$ is stress, $t$ is time and $D_{1}-D_{5}$ are material constants. To obtain the material constants, curve fitting is performed using Matlab software. This method [34] is based on least square method as mini- mizing the error function between theoretical values of the creep strain obtained using Eq. 2 and the experimental values as:

$$
R^{2}=\sum_{i}^{n}\left[\left(\varepsilon_{c r}\right)_{t}-\left(\varepsilon_{c r}\right)_{e x p}\right]^{2}
$$

Table 1 presents the values of material constants or parameters $D_{1}-D_{5}$ and corresponding data fit quality number $R^{2}$ values. The values of $R^{2}$ indicates the square of the correlation between the experimental values and the predicted values. The calculated values of $R^{2}$ are given in Table 1 and as it can be seen their values are close to one which indicates the acceptable quality of the regression. 
Parameters of the generalized time hardening model

Table 1

\begin{tabular}{|c|c|c|c|c|c|}
\hline Parameters & $D_{1}$ & $D_{2}$ & $D_{3}$ & $D_{4}=D_{5}$ & $R^{2}$ \\
\hline$T=25^{\circ} \mathrm{C}-$ Neat adhesive & $-2.20 \mathrm{e}-3$ & $5.64 \mathrm{e}-4$ & $-3.17 \mathrm{e}-5$ & 0.035 & 0.99 \\
\hline$T=25^{\circ} \mathrm{C}$ adhesive-Graphene & $-5.95 \mathrm{e}-4$ & $1.74 \mathrm{e}-4$ & $-9.73 \mathrm{e}-6$ & 0.035 & 0.98 \\
\hline$T=55^{\circ} \mathrm{C}-$ Neat adhesive & $-8.4 \mathrm{e}-3$ & $2.50 \mathrm{e}-3$ & $-1.59 \mathrm{e}-4$ & 0.035 & 0.98 \\
\hline$T=55^{\circ} \mathrm{C}$ adhesive-Graphene & $-5.2 \mathrm{e}-3$ & $1.80 \mathrm{e}-3$ & $-1.29 \mathrm{e}-4$ & 0.035 & 0.97 \\
\hline
\end{tabular}

\section{2. Single lap joints simulation and test results}

In the first step, adhesively bonded single lap joints were prepared to investigate the effect of RGO additive on their creep behavior. Adherend material is aluminum alloy 7075-T6 plate with $2 \mathrm{~mm}$ thickness and epoxy based Araldite 2011 is used for the bonding of the substrates. Two sets of samples were prepared: neat adhesive and adhesive-RGO composite with $0.5 \mathrm{wt} \%$ RGO. Adherend surface is prepared according to ASTM D1780 [23] recommendations.

In this procedure, adherends are cleaned with acetone then surfaces are treated with $\mathrm{SiC}$ abrasive paper and washed with water. Finally, adherends are etched with $\mathrm{H}_{2} \mathrm{SO}_{4}$.
Uniaxial creep tests were carried out using the prepared specimens and axial creep deformation of the specimens is measured experimentally. Eight sets of tests were carried out at 25 and $55^{\circ} \mathrm{C}$ and at two different stress levels for the bonded joints with neat adhesive and adhesive-RGO. Failure is occurred in tests at $55^{\circ} \mathrm{C}$, but in tests at $25^{\circ} \mathrm{C}$ the tests were stopped after 12 days.

Fig. 3 depicts the fractured surface of the joint after creep failure. The fractured surface shows that cohesive failure mode has been occurred in joints. This type of failure reflects the proper adherend surface preparation and joint.

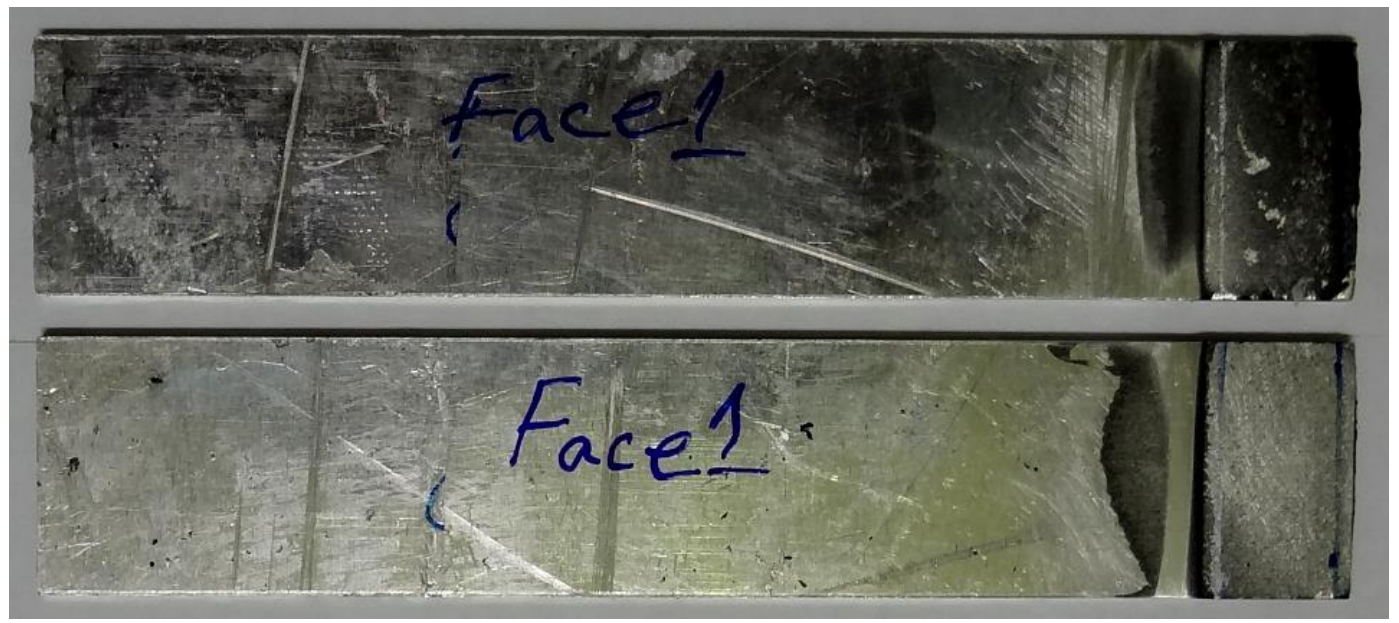

Fig. 3 Fractured surface of a single lap joint showing the cohesive failure
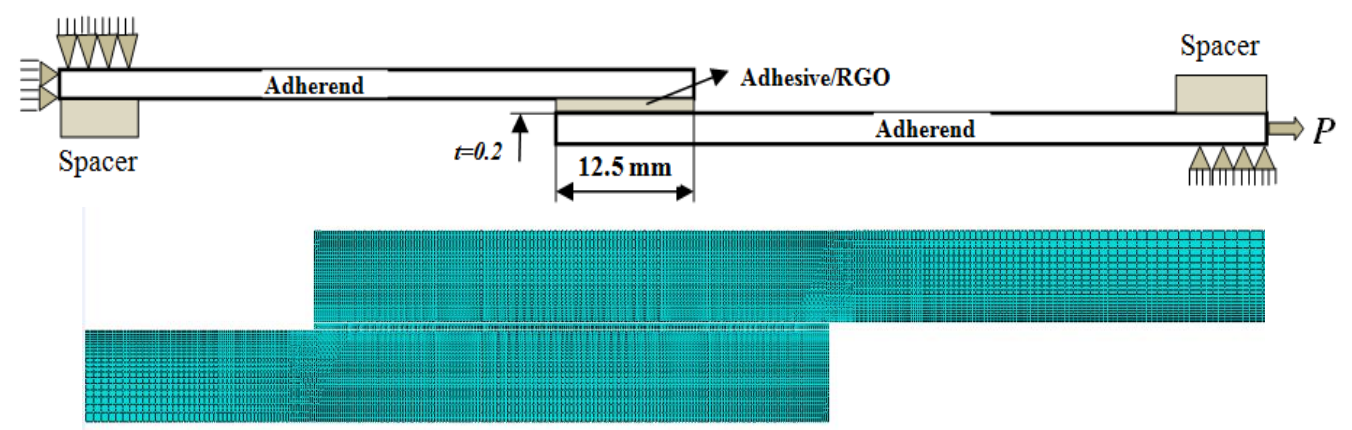

Fig. 4 Single lap joint: a - schematic model with dimensions and boundary conditions; b - FE model

Table 2

Mechanical properties of the adhesive-RGO composite [31]

\begin{tabular}{|c|c|c|c|}
\hline Sample designation, RGO, wt \% & Young's modulus, MPa & Poisson's ratio & Tensile strength, MPa \\
\hline Neat adhesive & $1802 \pm 20.1$ & $0.29 \pm 0.04$ & $26.36 \pm 0.48$ \\
\hline Adhesive-RGO 0.5 wt \% & $2105 \pm 22.4$ & $0.31 \pm 0.02$ & $34.35 \pm 0.63$ \\
\hline
\end{tabular}


In the second step, the developed generalized time hardening model is used to predict the creep behavior of a single lap joint using finite element based computer software ABAQUS. A two dimensional finite element model is used to model the single lap joint and its results are compared with the experimental results. Fig. 5, a and b illustrate the two dimensional finite element mesh, schematic drawing of the lap joint dimensions and boundary conditions which are used in the solution. The adherend material is Aluminum with elastic modulus, Poisson's ratio and thermal expansion coefficient of $E=70000 \mathrm{MPa}, v=0.3$ and $\alpha=2.2 \times 10^{-5}$ respectively [31]. Material properties of the adhesive are given in Table 1 [31]. In this study ABAQUSSTANDARD 6.12 finite element commercial software is used to carry out the numerical solutions. Quadratic plane strain elements 8-node which is referred as CPE8R in ABAQUS manual [25] is used to produce the finite element model. The total number of elements is 11,054 and nodes are 32,221. The analysis is performed considering an applied static force of $F=1.25$ and $2 \mathrm{kN}$. The proposed

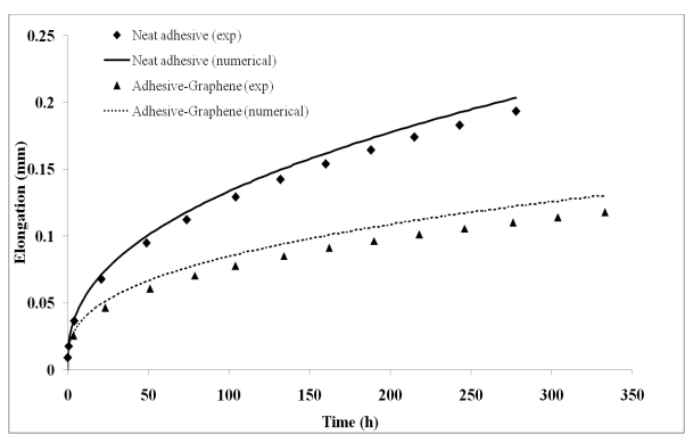

a

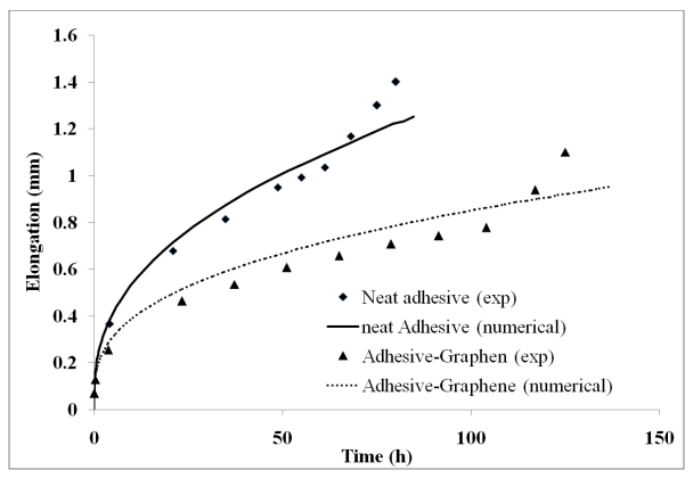

c model is introduced to the software with a user defined subroutine.

Fig. 5 shows the variation of the creep deformation with time for the samples. Fig. 5, a and b compare the creep elongation curves at $25^{\circ} \mathrm{C}$ under 1.25 and $2 \mathrm{kN}$ for the joints which are bonded with neat and adhesiveRGO. Also, Fig. 2, c and d present the creep elongation and creep-failure time for tests at $55^{\circ} \mathrm{C}$ with 1.25 and $2 \mathrm{kN}$. As it can be seen in this figure, incorporation of RGO greatly decreases the creep elongation; and therefore, it decreases the creep deformation and prolongs the creepfailure time of the joints at room and high temperatures. According to the experimental results, it is inferred that RGO additive enhances the creep performance of the adhesively bonded significantly. Also in this figure, the results of the numerical analyses are compared with the experimental data and good agreement can be observed. This shows that the finite element solution using the proposed model can simulate the creep behavior of the bonded joint with good accuracy at different stress and temperature levels.

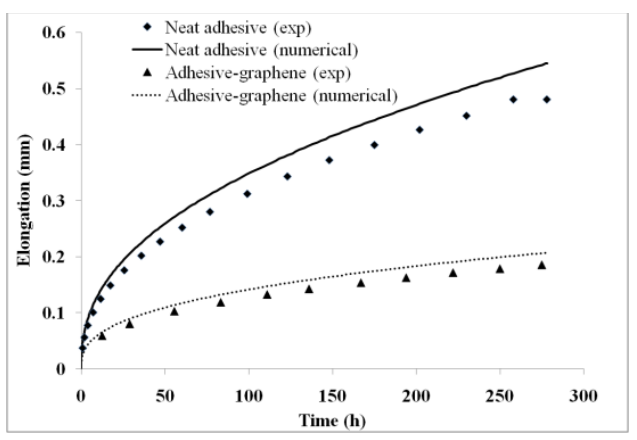

b

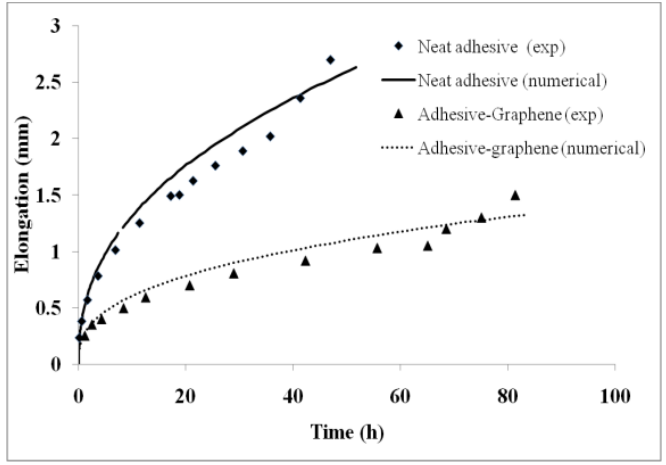

d

Fig. 5 Creep elongation -time curves for the single lap joints: a $-T=25^{\circ} \mathrm{C}$ and $F=1.25 \mathrm{kN} ; \mathrm{b}-T=25^{\circ} \mathrm{C}$ and $F=2 \mathrm{kN}$; c $-T=55^{\circ} \mathrm{C}$ and $F=1.25 \mathrm{kN} ; \mathrm{d}-T=55^{\circ} \mathrm{C}$ and $F=2 \mathrm{kN}$

\section{Conclusion}

In this research, uniaxial creep tests have been conducted on Araldite 2011 epoxy based adhesive in different stress and temperature levels. Using the results of these tests for both neat and RGO added adhesives, the strengthening effect of the added RGO on the creep behavior of the adherend has been observed.

Results show that, reinforced adhesive with RGO particles demonstrates lower creep deformation in room and high temperatures. Also it is observed that RGO increases the creep failure time of the epoxy adhesive significantly. The results reveal that; the single lap joints bonded with reinforced adhesive demonstrate lower creep deformation and higher creep failure time.

Additionally, the constitutive parameters of the generalized time hardening model has been obtained and this model is used to predict the creep behavior of the single lap joints. The results are compared with experimental data and good agreement is observed.

\section{References}

1. Su, N.; Mackie, R. I. 1993. Two-dimensional creep analysis of structural adhesive joints, International Journal of Adhesion and Adhesives 13(1): 33-40. 
https://doi.org/10.1016/0143-7496(93)90006-U.

2. Dean, G. D.; Broughton, W. 2005. A review of creep modelling for toughened adhesives and thermoplastics, National Physical Laboratory.

3. Brinson, H. F.; Brinson, L. C. 2007. Polymer engineering science and viscoelasticity: an introduction, Springer Science \& Business Media.

4. Lubliner, J. 2008. Plasticity theory, Courier Corporation.

5. Dean, G. 2007. Modelling non-linear creep behaviour of an epoxy adhesive, International Journal of Adhesion and Adhesives 27(8): 636-646. https://doi.org/10.1016/j.ijadhadh.2006.11.004.

6. Feng, C. W.; Keong, C. W.; Hsueh, Y. P.; Wang, Y. Y.; Sue, H. J. 2005. Modeling of long-term creep behavior of structural epoxy adhesives, International journal of adhesion and adhesives 25(5): 427-436. https://doi.org/10.1016/j.ijadhadh.2004.11.009.

7. Yu, X.; Crocombe, A.; Richardson, G. 2001 Material modelling for rate-dependent adhesives, International journal of adhesion and adhesives 21(3): $197-210$ https://doi.org/10.1016/S0143-7496(00)00051-8.

8. Majda, P.; Skrodzewicz, J. 2009. A modified creep model of epoxy adhesive at ambient temperature, International Journal of Adhesion and Adhesives 29(4): 396-404

https://doi.org/10.1016/j.ijadhadh.2008.07.010.

9. Yu, H.; Li, Z.; Wang, Q. J. 2013. Viscoelasticadhesive contact modeling: Application to the characterization of the viscoelastic behavior of materials, Mechanics of Materials 60: 55-65. https://doi.org/10.1016/j.mechmat.2013.01.004.

10. Roseley, A. S.; Rojo, E.; Ansell, M.P.; Smedley, D. 2011. Creep response of thixotropic ambient temperature cure adhesives measured by DMTA in static tension and shear, International Journal of Adhesion and Adhesives 31(6): 575-82. https://doi.org/10.1016/j.ijadhadh.2011.05.008.

11. Chiu, W. K.; Jones, R. 1995. Unified constitutive model for thermoset adhesive, FM73, International Journal of Adhesion and Adhesives 15(3): 131-136. https://doi.org/10.1016/0143-7496(95)91623-E.

12. Duncan, B.; Maxwell, A. 1999. Measurement methods for time-dependent properties of flexible adhesives, NPL.

13. Mortensen, F.; Thomsen, O. T. 2002. Analysis of adhesive bonded joints: a unified approach, Composites Science and Technology 62(7): 1011-1031. https://doi.org/10.1016/S0266-3538(02)00030-1.

14. Pandey, P.; Shankaragouda, H.; Singh, A.K. 1999. Nonlinear analysis of adhesively bonded lap joints considering viscoplasticity in adhesives, Computers \& structures 70(4): 387-413. https://doi.org/10.1016/S0045-7949(98)00168-0.

15. Pandey, P.; Narasimhan, S. 2001. Three-dimensional nonlinear analysis of adhesively bonded lap joints considering viscoplasticity in adhesives, Computers \& Structures 79(7): 769-783. https://doi.org/10.1016/S0045-7949(00)00160-7.

16. Ferrier, E.; Michel, L.; Jurkiewiez, B.; Hamelin, P. 2011. Creep behavior of adhesives used for external FRP strengthening of RC structures, Construction and Building Materials 25(2): 461-467. https://doi.org/10.1016/j.conbuildmat.2010.01.002.

17. Choi, K. K.; Reda Taha, M. M. 2013. Rheological modeling and finite element simulation of epoxy adhesive creep in FRP-strengthened RC beams, Journal of Adhesion Science and Technology 27(5-6): 523-35. https://doi.org/10.1080/01694243.2012.687557.

18. Flahaut, E.; Peigney, A.; Laurent, C.; Marliere, C.; Chastel, F.; Rousset, A. 2000. Carbon nanotubemetal-oxide nanocomposites: microstructure, electrical conductivity and mechanical properties, Acta Materialia 48(14): 3803-12. https://doi.org/10.1016/S1359-6454(00)00147-6.

19. Geng, Y.; Liu, M.Y.; Li, J.; Shi, X.M.; Kim, J. K. 2008. Effects of surfactant treatment on mechanical and electrical properties of CNT/epoxy nanocomposites, Composites Part A: Applied Science and Manufacturing 39(12): 1876-1883. https://doi.org/10.1016/j.compositesa.2008.09.009.

20. Gojny, F. H.; Wichmann, M. H.; Fiedler, B.; Schulte, K. 2005. Influence of different carbon nanotubes on the mechanical properties of epoxy matrix composites-a comparative study, Composites Science and Technology 65(15): 2300-2313. https://doi.org/10.1016/j.compscitech.2005.04.021.

21. Karapappas, P.; Vavouliotis, A.; Tsotra, P.; Kostopoulos, V.; Palpetis, A. 2009. Enhanced fracture properties of carbon reinforced composites by the addition of multi-wall carbon nanotubes, Journal of Composite Materials 43(9): 977-985. https://doi.org/10.1177/0021998308097735.

22. Siengchin, S.; Karger-Kocsis, J. 2009. Structure and creep response of toughened and nanoreinforced polyamides produced via the latex route: Effect of nanofiller type, Composites Science and Technology 69(5): 677-783

https://doi.org/10.1016/j.compscitech.2009.01.003.

23. Varela-Rizo, H.; Weisenberger, M.; Bortz, D.R.; Martin-Gullon, I. 2010. Fracture toughness and creep performance of PMMA composites containing micro and nanosized carbon filaments, Composites Science and Technology 70(7): 1189-1195. https://doi.org/10.1016/j.compscitech.2010.03.005.

24. Yang, J.-L.; Zhang, Z.; Schlarb, A.K.; Friedrich, K. 2006. On the characterization of tensile creep resistance of polyamide 66 nanocomposites. Part I. Experimental results and general discussions, Polymer 47(8): 27912801. https://doi.org/10.1016/j.polymer.2006.02.065.

25. Yao, Z.; Wu, D.; Chen, C.; Zhang, M. 2013. Creep behavior of polyurethane nanocomposites with carbon nanotubes, Composites Part A: Applied Science and Manufacturing 50: 65-72. https://doi.org/10.1016/j.compositesa.2013.03.015.

26. Khan, U.; May, P.; Porwal, H.; Nawaz, K.; Coleman, J. N. 2013. Improved adhesive strength and toughness of polyvinyl acetate glue on addition of small quantities of graphene, ACS applied materials \& interfaces 5(4): 1423-1428. https://doi.org/10.1021/am302864f.

27. Novoselov, K. S.; Fal, V.; Colombo, L.; Gellert, P.; Schwab, M.; Kim, K. 2012. A roadmap for graphene, Nature 490(7419): 192-200.

https://doi.org/10.1038/nature11458. 
28. Zandiatashbar, A.; Picu, C.R.; Koratkar, N. 2012. Control of epoxy creep using graphene, Small 8(11): 1676-1682.

https://doi.org/10.1002/smll.201102686.

29. Tang, L.C.; Wang, X.; Gong, L.X.; Peng, K.; Zhao, L.; Chen, Q.; Wu, L.B.; Jiang, J.X.; Lai, G.Q. 2014. Creep and recovery of polystyrene composites filled with graphene additives, Composites Science and Technology 91: 63-70. https://doi.org/10.1016/j.compscitech.2013.11.028.

30. Wang, X.; Gong, L.X.; Tang, L.C.; Peng, K.; Pei, Y.B.; Zhao, L.; Wu, L.B.; Jiang, J.X. 2015. Temperature dependence of creep and recovery behaviors of polymer composites filled with chemically reduced graphene oxide, Composites Part A: Applied Science and Manufacturing 69: 288-298. https://doi.org/10.1016/j.compositesa.2014.11.031.

31.Sadigh, M. A. S.; Marami, G. 2016. Investigating the effects of reduced graphene oxide additive on the tensile strength of adhesively bonded joints at different extension rates, Materials \& Design 92: 36-43. https://doi.org/10.1016/j.matdes.2015.12.006.

32. Zehsaz, M.; Vakili-Tahami, F.; Saeimi-Sadigh, M.A. 2014. Parametric study of the creep failure of double lap adhesively bonded joints, Materials \& Design 64: 520-526. https://doi.org/10.1016/j.matdes.2014.08.003.

33. Zehsaz, M.; Vakili-Tahami, F.; Saeimi-Sadigh, M.A. 2015. Modified creep constitutive equation for an epoxy-based adhesive with nonlinear viscoelastic behavior, The Journal of Strain Analysis for Engineering Design 50(1): 4-14. https://doi.org/10.1177/0309324714554965.

34. The MathWorks. 2014. Matlab User's Guide. The MathWorks, Inc., Natick, MA.
Gholamreza Marami, S. Adib Nazari, S. Ali Faghidian, Farid Vakili-Tahami

\section{EFFECT OF REDUCED GRAPHENE OXIDE REINFORCEMENT ON CREEP BEHAVIOR OF ADHESIVELY BONDED JOINTS}

\section{S u m m a r y}

The creep behaviour of adhesively bonded joints is one of the major concerns in modern industry due to their application at relatively high temperature. In this research, the effect of added RGO on the creep behaviour of the Araldite 2011 adhesive is investigated. Uni-axial creep tests have been carried out on neat Araldite 2011 and RGO added adhesive at different stress and temperature levels. It has been shown that adhesive with RGO particles demonstrate higher creep resistance. Also, general time hardening models are developed for both materials and their constitutive coefficients have been determined using creep test data. Based on these models, the creep behavior of single lap joints has been simulated using finite element solution method. The results are compared with experimental data and good agreement has been observed that reflects the robustness of the model. It has been shown that joints with added RGO adhesive have significantly higher creep strength.

Keywords: creep behavior, RGO, joints.

Received November 02, 2016 Accepted October 13, 2017 